GU J Sci, Part C, 6(1): 79-89 (2018)

Gazi Üniversitesi
Fen Bilimleri Dergisi
PART C: TASARIM VE TEKNOLOJI
dergipark.gov.tr/http-gujsc-gazi-edu-tr

\title{
Metal Şekillendirme Proseslerinde Sac Açınım Geometrisinin Sonlu Elemanlar Yöntemi ile Geliştirilmesi
}

\author{
Emre ESENER ${ }^{1, *}$ Emre SÖNMEZ $^{1}$, Mehmet FIRAT $^{2}$

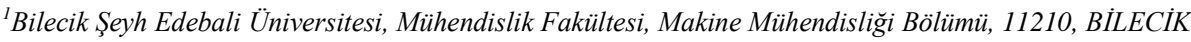 \\ ${ }^{2}$ Sakarya Üniversitesi, Mühendislik Fakültesi, Makine Mühendisliği Bölümü, 54050, SAKARYA
}

$\ddot{\mathbf{O} z}$

Makale Bilgisi

Basvuru: 06/06/2017

Düzeltme: 23/11/2017

Kabul: 14/12/2017

Anahtar Kelimeler

Sac metal şekillendirme

Açınım tasarımı

Sonlu elemanlar analizi

Keywords

Sheet metal forming Initial blank design Finite element analysis
Ağırlık/dayanım avantajlarından dolayı sac metal malzemeler bir çok endüstriyel uygulamada tercih edilmektedir. Proses tasarımı, sac metal şekillendirme yöntemleri açısından oldukça kritik bir adımdır. Sac açınım geometrisinin belirlenmesi proses tasarımı açısından oldukça önemlidir. Optimum açınım geometrisinin belirlenmesi ile malzeme fire miktarları önemli oranlarda azaltılabilmektedir. Bu çalışmada kare çekme prosesi için, alüminyum 5754 alaşımı kullanılarak proses parametrelerini ve ürün geometrisini dikkate alan sonlu elemanlar yöntemi tabanlı bir sac açınım geliştirme yöntemi sunulmuştur. Elde edilen yeni sac açınımı ile malzeme fire miktarında önemli bir kazanç elde edilmiş ve şekillendirilebilirlik açısından daha güvenli bir geometri oluşturulmuştur.

\section{Development of Initial Blank Geometry in Sheet Metal Forming Processes Using Finite Element Analysis}

\begin{abstract}
Sheet metal parts have a wide usage are due to their weight/strength ratio. Process design is a critical step for sheet metal forming processes. Determining initial blank geometry is crucial for process design. Material wastage can be reduced by obtaining the optimum initial blank geometry. In this study, a methodology, for developing initial blank geometry for square drawing process using aluminum 5754 alloy considering process parameters and product geometry based on finite element analysis, is presented. A crucial material acquisition and a safe geometry regards to formability properties is obtained with the new blank geometry.
\end{abstract}

\section{GİRIŞ (INTRODUCTION)}

Günümüzde otomotiv sektörü ülkemiz endüstrisinin lokomotif sektörlerinden birisidir. Otomobillerde ağırlık/dayanım avantajlarından dolayı yüzlerce sac metal parça kullanıldığından sac metal formlama işlemleri otomotiv sektörü için vazgeçilmez bir üretim prosesidir. Endüstride yeni model bir araç geliştirilmesi sonucunda araçta yer alan sac metal parçalarda geometri, malzeme v.b. gibi değişiklikler yapıldığından kalıp yüzeylerinde de bu kapsamda değişikliğe gidilmesi bir zorunluluktur. Özellikle otomotiv sektörü gibi seri üretim yapılan ve büyük parçalara sahip bir sektörde bu değişikliklerin hızlı bir şekilde gerçekleştirilmesi gerekmektedir. Bu nedenle, kalıp yüzeylerinin tasarımları ve üretim prosesleri geliştirildikten sonra, ilgili parça geometrisi hedef toleranslara ulaşacak şekilde imalat sürecine entegre edilmelidir.

Otomotiv sektöründe kullanılan sac metal malzemelerin gelişimi de hızlı bir ilerleyiş göstermektedir. Zaman içerisinde birçok yeni malzeme tasarımı yapılmakta ve çeşitlilik artmaktadır. Bu anlamda, geliştirilen malzemelerin mekanik özelliklerinin farklı olmasından ötürü şekillendirilebilirlikleri de farklılık göstermektedir. Otomotiv sektöründe kullanılan malzemeler oldukça kompleks geometrilere sahiptirler dolayısı ile kalıp yüzeyleri de karmaşıtır. Bu durum prosesin başarılı bir şekilde gerçekleştirilmesini de zorlaştırmaktadır. Bu nedenle de proseste birçok problemle karşılaşılmaktadır. 
Otomotiv sektöründe formlama proseslerinin karmaşıklığına, sürekli güncellenen parça geometrileri ve parçalar da eklendiğinde bu kapsamda proses tasarımını gerçekleştiren metot mühendisliğinin önemi ortaya çıkmaktadır. Seri üretimin bulunduğu endüstrilerde, üretimin devamlılığı açısından proses tasarımlarının oldukça hızlı bir şekilde gerçekleştirilmesi gerekmektedir. Sac metallerin geometrik yapıları ve montaj proseslerinden dolayı, tasarım ve metot mühendislerinin, istenilen ölçü toleranslarına ve parça yüzeyine sahip bir şekilde ürünü formlama hataları olmadan verebilecek bir kalıp takımını tasarlamaları ve üretmeleri gerekmektedir.

Kalıp geometrilerinin yanı sıra sac parçaların açınım tasarımları da başı başına bir mühendislik problemidir. Preste formlama işlemlerinde sac metalin kalıp takımları arasına yerleştirilen formlanmamış ilk geometrisine sac açınımı denilmektedir. Açınım tasarımının belirli mühendislik yaklaşımları ile gerçekleştirilmesi, üretimde malzeme tasarrufu açısından oldukça önem arz etmektedir. Bu süreç üretim maliyetine doğrudan etki eden oldukça önemli bir adımdır. Bu doğrultuda, açınım tasarımları optimize edilerek minimum malzeme firesi verilerek en yüksek verim ve maliyette bir tasarımın gerçekleştirilmesi gerekmektedir. Aynı zamanda geliştirilen açınım geometrisinin yine form hataları açısından incelenmiş ve ürün geometrisinin en yüksek doğrulukta elde edileceği bir tasarımda olması gerekmektedir.

Literatürde bu doğrultuda yapılan çalışmalar incelendiğinde genellikle nümerik iterasyon tabanlı algoritmaların kullanıldığı görülmektedir [1-5]. Fakat nümerik yöntemlerin her geometri ya da malzeme için geçerliliği tartışmalı bir konudur. Ayrıca bu tarz yaklaşımların endüstrideki bilgi birikimi ve zaman kaygısı nedeni ile yaygın bir geçerliliği olamamaktadır. Nümerik yöntemlerin dışında NURBS (NonUniform Rational Bezier-Splines) eğrileri kullanılarak da geliştirilen sac açınım tasarım yöntemleri de yer almaktadır [6-9]. Bu eğriler belirli kontrol noktalarından geçen uniform olmayan karmaşık eğrilerdir. $\mathrm{Bu}$ yöntem nümerik iterasyon algoritmalarına göre daha geçerli olmakla birlikte eğriler açısından belirlenecek olan kontrol noktaları oldukça kritiktir. Bu yöntemde kontrol noktaları değiştirildiğinde elde edilen eğri sınırları da değişkenlik gösterdiğinden bir karar verme mekanizmasının sürece eklenilmesi gerekmektedir. Bu durum yine zaman kaybına neden olmaktadır [10].

$\mathrm{Bu}$ yöntemlerin dışında proses parametrelerinin ve ürüne ait topolojik özelliklerin dikkate alındığı açınım tasarımlarının gerçekleştirilmesi en hassas sonuçların elde edilmesini sağlayacaktır. Bu yöntem, hem endüstri tecrübesine yatkın hem de proses tabanlı bir yöntem olduğundan proses parametreleri değiştikçe açınım tasarımının da değişimine imkan sağlayacaktır. Bu tarz bir yöntemin uygulanması endüstri açısından hem daha anlaşılır hem de proses tabanlı olduğundan daha gerçekçi sonuçların elde edilmesi beklentisini doğurmaktadır. Bu çalışmada bu kapsamı içeren bir açınım geliştirme metodolojisi sunulmuştur.

Endüstride kullanılan parça geometrilerinin karmaşık oluşu malzeme etkisinin anlaşılabilirliğini zorlaştırmaktadır. $\mathrm{Bu}$ nedenle malzemelerin plastik şekillenme davranışını belirlemek adına karmaşık formlama proseslerini temel bükme problemlerine ya da daha basit formlama problemlerine indirgeyen geometriler geliştirilmekte ve bu geometrilerle denemeler yapılmaktadır. $\mathrm{Bu}$ testler, benzetim testleri olarak adlandırılırlar. V kalıpta serbest bükme, U kanal çekme, kare çekme gibi testler benzetim testleri grubundadır. Bu testler sonrasında malzemenin şekillendirilebilirliği hakkında bilgi edinilir. Benzetim testlerinde proses parametrelerinin de geometri üzerine etkileri tespit edilebilmektedir. Bu testler aynı zamanda deneme-yanılma sürecini ortadan kaldırmak amacı ile bilgisayar ortamında da geliştirilerek süreçteki zaman kayıplarının en aza indirilmesi amaçlanmaktadır. Diğer nümerik yaklaşımlarla karşılaştırıldığında sonlu elemanlar yöntemi, sac metal formlama yöntemlerinde bilgisayar destekli tasarımda en sık kullanılan yöntemdir. Tasarım ve metot mühendisleri proses tasarlanırken karşılaşılabilecek problemleri tasarım prosedürünün erken dönemlerde tespit edip telafi edebilmelidirler. Böylelikle, deneme-yanılma süreci için gereken zaman ve maliyet kayıpları oldukça azaltılmış olmaktadır. Formlama prosesleri, hassas malzeme davranışlarının tespiti gerektiğinden, büyük deformasyonlarla çalışıldığından ve kalıp takımları ve malzeme arasında karmaşık temas durumları bulunduğundan sonlu elemanlar yöntemi açısından karmaşık problemlerdir. Sac metal formlama yöntemlerinin sonlu elemanlar analizlerinde, malzeme davranışının doğru ve hassas bir şekilde tanımlanması tahmin sonuçları üzerinde oldukça etkilidir. Formlama yöntemlerinde malzemede meydana gelen plastik deformasyonların modellenebilmesi için malzemenin elastik ve plastik davranışlarını tanımlayan malzeme modellerinin tespiti metot mühendisliği açısından oldukça kritiktir. Bu kapsamda 
malzeme modelleri için gerekli malzeme parametrelerinin de hassas bir biçimde belirlenmesi aynı şekilde önem arz etmektedir [11].

$\mathrm{Bu}$ çalışmada, benzetim testi gruplarından malzemelerin şekillendirilebilirlik özelliklerinin incelendiği kare çekme testi referans alınarak sonlu elemanlar yöntemi ile proses tabanlı bir açınım geliştirme yöntemi sunulmuştur. Malzeme olarak otomotiv sektöründe yakıt tankları gibi derin çekme amaçlı proseslerde kullanılan alüminyum 5754 alaşımı kullanılmıştır.

\section{MALZEME VE YÖNTEM (MATERIAL AND METHOD)}

Alüminyum 5000 serisi yüksek mukavemeti, güçlü korozyon dayanımı ve yüksek şekillendirilebilirlik özelliklerinden dolayı otomotiv endüstrisinde özellikle yakıt tankı gibi derin çekme uygulamalarında yaygın olarak kullanılmaktadır [12]. Şekil 1'de AA-5754-O alüminyum alaşımından üretilmiş bir yakıt tank1 örneği yer almaktadır. Çalışmada $1 \mathrm{~mm}$ kalınlığına sahip AA5754-O alüminyum alaşımı sac malzeme kullanılarak kare çekme prosesi altında şekillendirme işlemi gerçekleştirilmiştir. Çalışmada kullanılan malzemeye ait mekanik özellikler ise Tablo 1'de verilmiştir. İlk olarak üst kalıp, zımba, pot çemberi ve sac açınımından oluşan kalıp takımları bilgisayar ortamında modellenmiştir (Şekil 2).

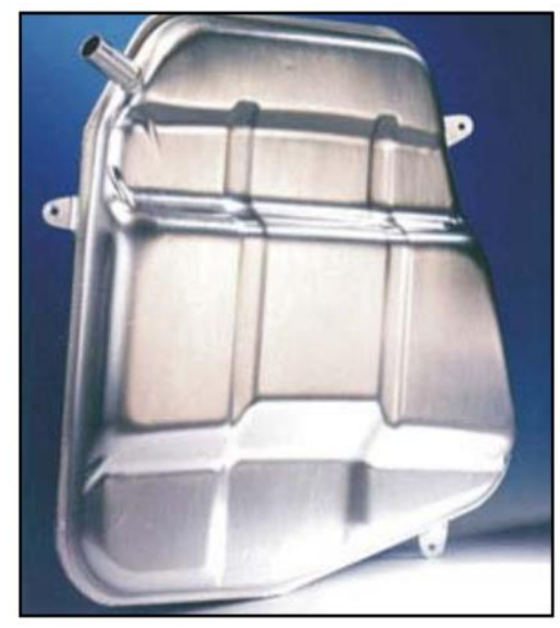

Şekil 1: Alüminyum yakıt tankı prototipi [13]

Tablo 1: AA 5754 alaşımına ait mekanik özellikler

\begin{tabular}{|c|c|c|c|c|c|c|}
\hline $\begin{array}{c}\text { Yağunluk } \\
{\left[\mathbf{g} / \mathbf{m m}^{3} \text { ] }\right.}\end{array}$ & $\begin{array}{c}\text { Elastik } \\
\text { Modülüi } \\
{[\mathbf{G P a}]}\end{array}$ & $\begin{array}{c}\text { Poisson } \\
\text { Oranı }\end{array}$ & $\begin{array}{c}\text { Akma } \\
\text { Gerilmesi } \\
{[\mathbf{M P a}]}\end{array}$ & $\begin{array}{c}\text { Mukavemet } \\
\text { Katsayısı K, } \\
{[\mathbf{M P a}]}\end{array}$ & $\begin{array}{c}\text { Pekleşme } \\
\text { Üsteli, } \mathbf{n}\end{array}$ & $\begin{array}{c}\text { Anisotropi } \\
\text { Katsayısı, } \\
\mathbf{r}\end{array}$ \\
\hline $2.7 \times 10^{-9}$ & 70 & 0.33 & 91,5 & 455,5 & 0.33 & 0,72 \\
\hline
\end{tabular}




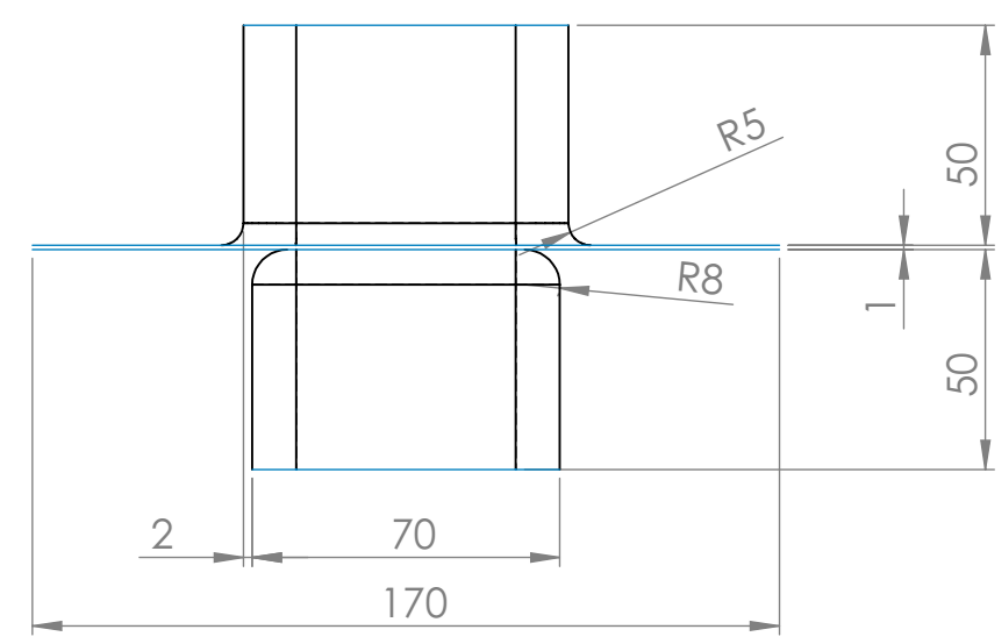

Şekil 2: Kare çekme prosesi kalıp takımı

Çalışma kapsamında gerçekleştirilen sonlu elemanlar analizlerinde malzeme plastisite modellemesi aşamasında Hill-48 malzeme modeli kullanılmıştır. R.Hill, 1948 yılında von Mises kriterini genelleştirerek bir anizotropik akma kriteri geliştirmiştir [14]. Malzemenin üç ortogonal simetri düzleminde anizotropiye sahip olması gerekmektedir. Kriter bir ikinci dereceden bir fonksiyon olarak şu şekilde yazılabilir;

$$
2 f\left(\sigma_{i j}\right) \equiv F\left(\sigma_{y}-\sigma_{z}\right)^{2}+G\left(\sigma_{z}-\sigma_{x}\right)^{2}+H\left(\sigma_{x}-\sigma_{y}\right)^{2}+2 L \tau_{y z}^{2}+2 M \tau_{z x}^{2}+2 N \tau_{x y}^{2}=1
$$

Burada f, akma fonksiyonu, F, G, H, L, M, N malzemenin anizotropi parametreleri ve $\mathrm{x}, \mathrm{y}, \mathrm{z}$ asal anizotropik eksenlerdir. Düzlem gerilme durumu için ise Hill 48 akma kriteri şu hali alır,

$$
2 \mathrm{f}\left(\sigma_{\mathrm{ij}}\right)=(\mathrm{G}+\mathrm{H}) \sigma_{\mathrm{x}}^{2}-2 \mathrm{H} \sigma_{\mathrm{x}} \sigma_{\mathrm{y}}+(\mathrm{H}+\mathrm{F}) \sigma_{\mathrm{y}}^{2}+2 \mathrm{~N} \tau_{\mathrm{xy}}^{2}=1
$$

Sac metal formlama yöntemlerinde, Lankford parametreleri $r_{0}, r_{45}, r_{90}$ ve asal anizotropik yönlerdeki akma gerilmeleri $X=\sigma_{0}, Y=\sigma_{90}$ olarak isimlendirilir. Lankford parametreleri ve $F, G, H$ katsayıları arasındaki ilişki şu şekilde gösterilebilir;

$$
\mathrm{r}_{0}=\frac{\mathrm{H}}{\mathrm{G}}, \quad \mathrm{r}_{90}=\frac{\mathrm{H}}{\mathrm{F}}, \quad \sigma_{45}=\frac{\mathrm{H}}{\mathrm{F}+\mathrm{G}}-\frac{1}{2}
$$

Akma gerilmeleri ve Lankford parametreleri arasındaki ilişki verilirse,

$$
\frac{\sigma_{0}}{\sigma_{90}}=\sqrt{\frac{r_{0}\left(1+r_{90}\right)}{r_{90}\left(1+r_{0}\right)}}
$$

Gerilme tensörünün asal eksenlerinin, anizotropik eksenlerle çakışık olduğu durumda $\left(\sigma_{x}=\sigma_{1}, \sigma_{y}=\sigma_{2}\right.$, $\tau_{\mathrm{xy}}=0$ ), Hill 48 akma kriteri asal gerilmelere bağlı olarak şu şekilde yazılabilir,

$$
\sigma_{1}^{2}-\frac{2 r_{0}}{1+r_{0}} \sigma_{1} \sigma_{2}+\frac{r_{0}+r_{90}}{r_{90}\left(1+r_{0}\right)} \sigma_{2}^{2}=\sigma_{0}^{2}
$$

ya da Denklem 2.4'e göre,

$$
\sigma_{1}^{2}-\frac{2 r_{0}}{1+r_{0}} \sigma_{1} \sigma_{2}+\frac{r_{0}+r_{90}}{r_{90}\left(1+r_{0}\right)} \sigma_{2}^{2}=\frac{r_{0}\left(1+r_{90}\right)}{r_{90}\left(1+r_{0}\right)} \sigma_{90}^{2}
$$

Denklem 2.5 ve 2.6 düzlem gerilme durumu için akmayı tanımlar ve $r_{0}-r_{90}$ parametrelerine bağlı bir elips ailesini temsil eder [15]. 


\subsection{Sonlu Elemanlar Analizleri (Finite Element Analysis)}

Çalışmada sonlu elemanlar analizleri ticari bir sonlu elemanlar kodu olan Ls-Dyna (Dynaform) yazılımı kullanılarak gerçekleştirilmiştir. Bu aşamada ilk olarak, kare çekme prosesi için tasarlanan kalıp takımı için ă̆ yapısı oluşturulmuştur. Kalıp takımının ağ yapısı Şekil 3’te gösterilmiştir. Ağ yapısının oluşturulmasının ardından proses parametreleri ve sınır koşulları tanımlanarak simülasyonlar gerçekleştirilmiştir. Çalışmada kullanılan proses ve sonlu elemanlar hesaplama parametreleri Tablo 2'de verilmiştir. Kare çekme prosesi simülasyonlarında $1 \mathrm{~mm}$ kalınlığında alüminyum 5754 alaşımı ve başlangıç sac açınım geometrisi olarak 170x170 mm boyutlarında kare açınım kullanılmıştır. Sonlu elemanlar analizlerinde sac açınımı eleman boyutu $1 \mathrm{~mm}$ olarak belirlenmiştir (Şekil 4). Kare çekme prosesi formlama ve kesme olmak üzere 2 operasyonlu olarak tasarlanmış ve sonlu elemanlar analizleri de bu doğrultuda gerçekleştirilmiştir. Kesme operasyonu için sacın kesme işleminin gerçekleştirileceği bir kesim hattı belirlenmiştir. Bu kesim hattı kalıp radyuslerinin bitiş geçirilerek ürün geometrisi elde edilmiştir. Belirlenen kesim hattının kalıp üzerindeki konumu Şekil 5'te gösterilmiştir.

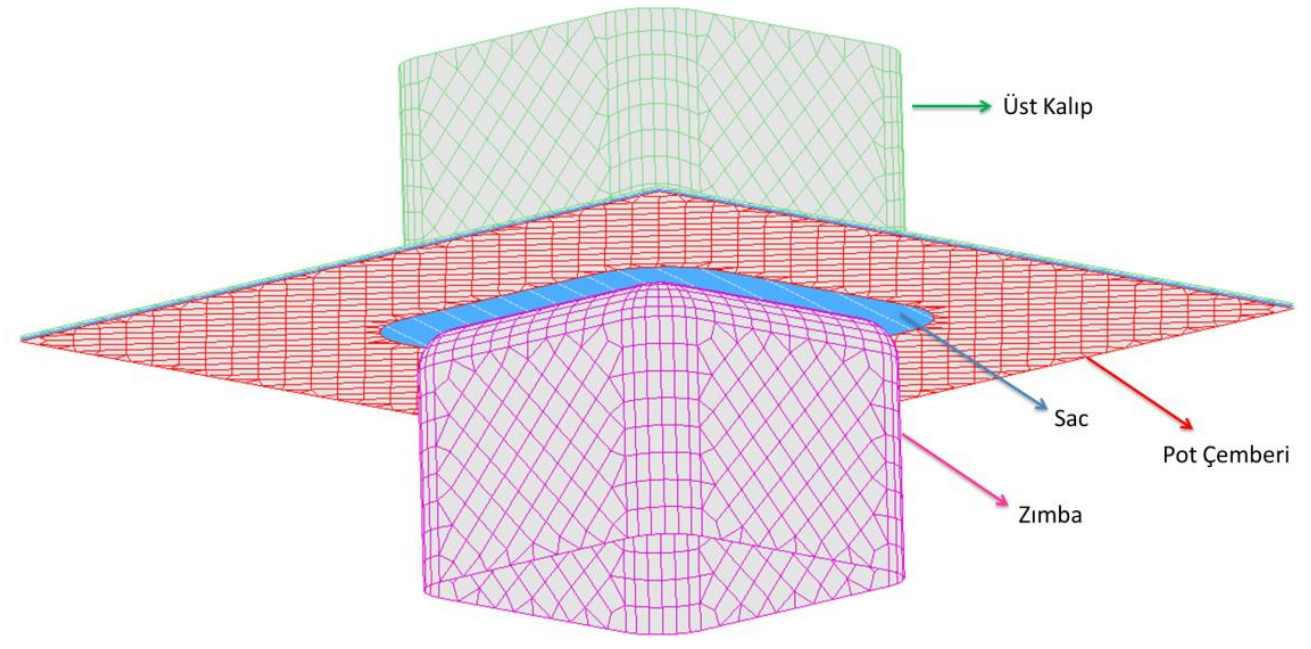

Şekil 3: Kare çekme prosesi kalıp takımı ă̆ yapısı

Tablo 1: Proses ve Sonlu Elemanlar Hesaplama Parametreleri

\begin{tabular}{|l|l|}
\hline Kalıp Hızı & $2000 \mathrm{~mm} / \mathrm{s}$ \\
\hline Pot Çemberi Kuvveti & $20.000 \mathrm{~N}$ \\
\hline Sürtünme Katsayısı & 0.125 \\
\hline Çekme Mesafesi & $30 \mathrm{~mm}$ \\
\hline Sac Eleman Boyutu & $1 \mathrm{~mm}$ \\
\hline Eleman Formülasyonu & Tam İntegrasyonlu Kabuk Eleman \\
\hline İntegrasyon Nokta Sayısı & 7 \\
\hline
\end{tabular}




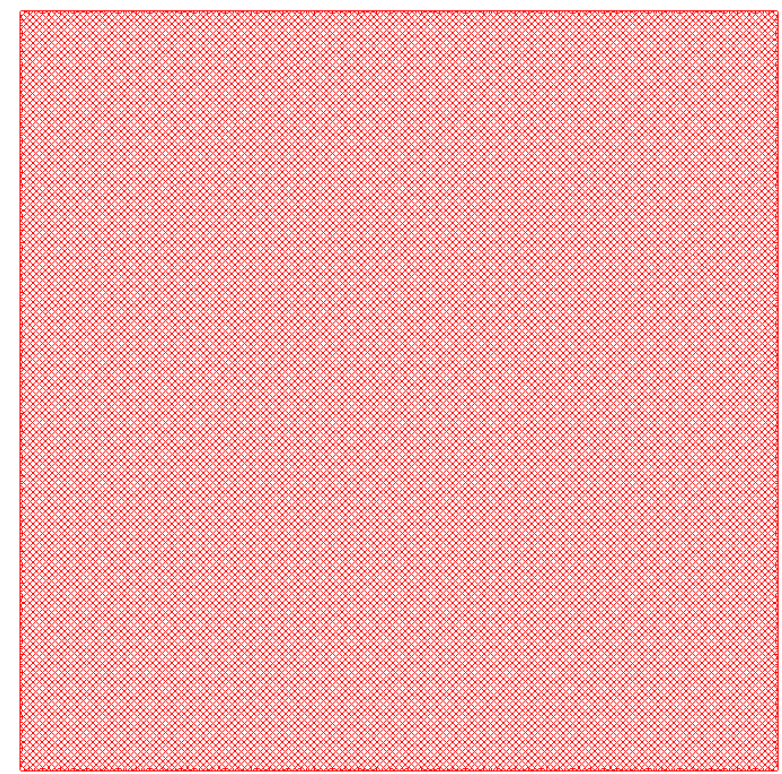

Şekil 4: Başlangıç açınım geometrisine ait ă̆ yapısı

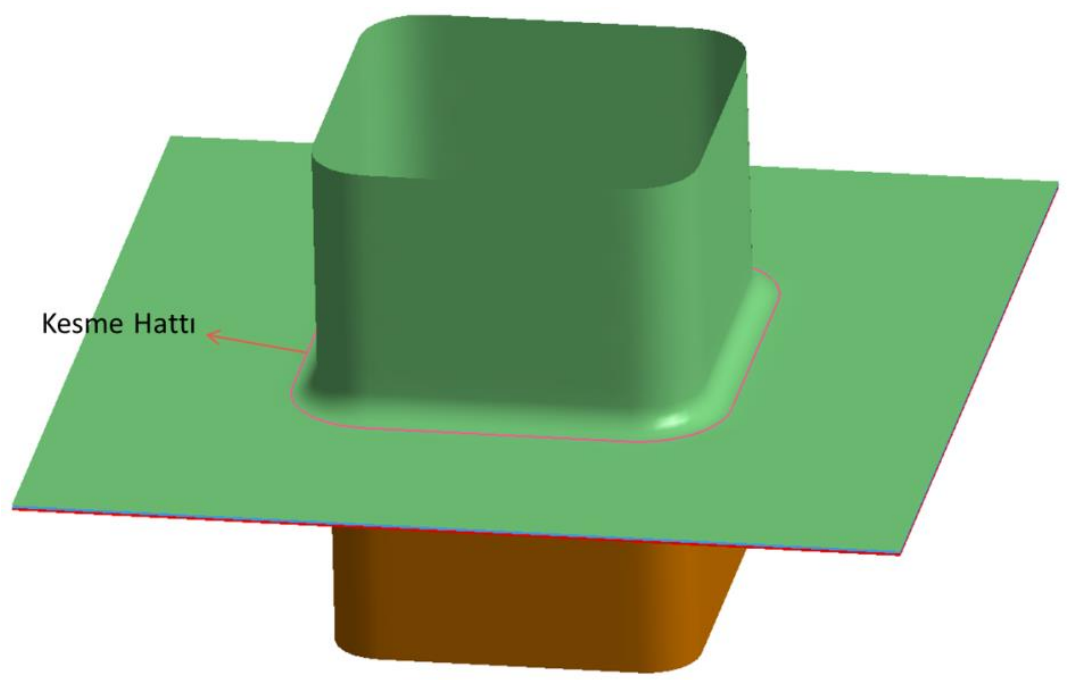

Şekil 5: Kesme hattının kalıp üzerindeki konumu

\subsection{Yeni Sac Açınım Geometrisinin Geliştirilmesi (Development of New Initial Blank Geometry)}

Yapılan çalışmada ikinci bir sac açınımın geliştirilmesindeki amaç, mevcut durumdaki malzeme fire miktarını azaltmak ve maliyet kazancı sağlamaktır. Bu doğrultuda proses parametrelerinden çekme miktarı ve ürün geometrisi dikkate alınarak geometrisi malzeme fire miktarını azaltacak şekilde tasarlanan bir sac açınımı geliştirilmiştir. Yeni açınım geometrisi için öncelikle ürüne ait sınır formu gerekmektedir ki bu form mevcut kare çekme prosesi için kesme hattı olarak tanımlanan kalıp radyuslarının bittiği hattır. Fakat çekme işlemi sırasında sac malzeme kalıp içerisine akacağından kesme hattı sınır hat olarak belirlendiği durumda ürün geometrisinin elde edilmesi mümkün olmamaktadır. $\mathrm{Bu}$ nedenle daha geniş bir sınır hattının seçilmesi gerekmektedir. Bu doğrultuda sac kalınlığı da dikkate alınarak mevcut kalıp takımı için sac kalınlığının 10 katı olacak şekilde kesme hattının $10 \mathrm{~mm}$ uzağında yeni bir referans sınır hattı belirlenmiştir (Şekil 6). Bu sınır hattı yeni açınım geometrisi için sınır boyutları temsil etmektedir. İkinci adım olarak yeni sac geometrisinin bu sınır içerisinde nasıl bir geometriye sahip olacağının belirlenmesidir. Bu doğrultuda ürün geometrisini verecek şekilde yeni sac açınımı sonlu elemanlar analizi ile belirlenmiştir. Elde edilen yeni sac açınım geometrisinin boyutları ve ilk açınım ile karşılaştırılması Şekil 7'de verilmiştir. Çalışmanın sonraki adımında sonlu elemanlar analizleri yeni sac açınımı için gerçekleştirilmiştir. İkinci sac açınımında da yine $1 \mathrm{~mm}$ eleman boyutunda ağ yapısı kullanılmıştır (Şekil 8). Yeni sac açınımı için kullanılan proses ve sonlu elemanlar hesaplama parametreleri ilk açınımda kullanılan parametrelerle aynı olacak şekilde seçilmiştir. 


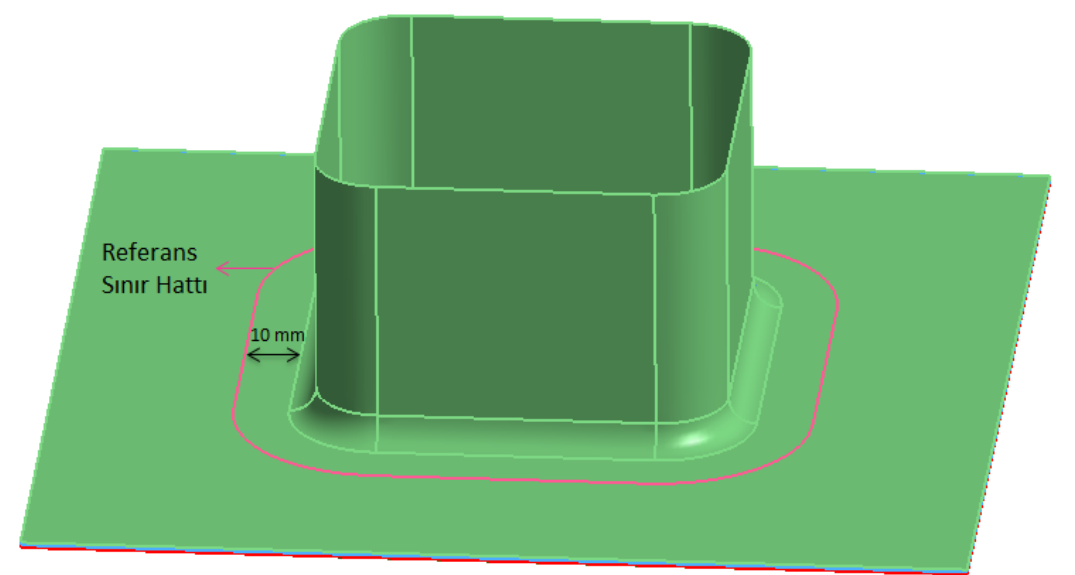

Şekil 6: Yeni sac açınımı için belirlenen referans sınır hattı

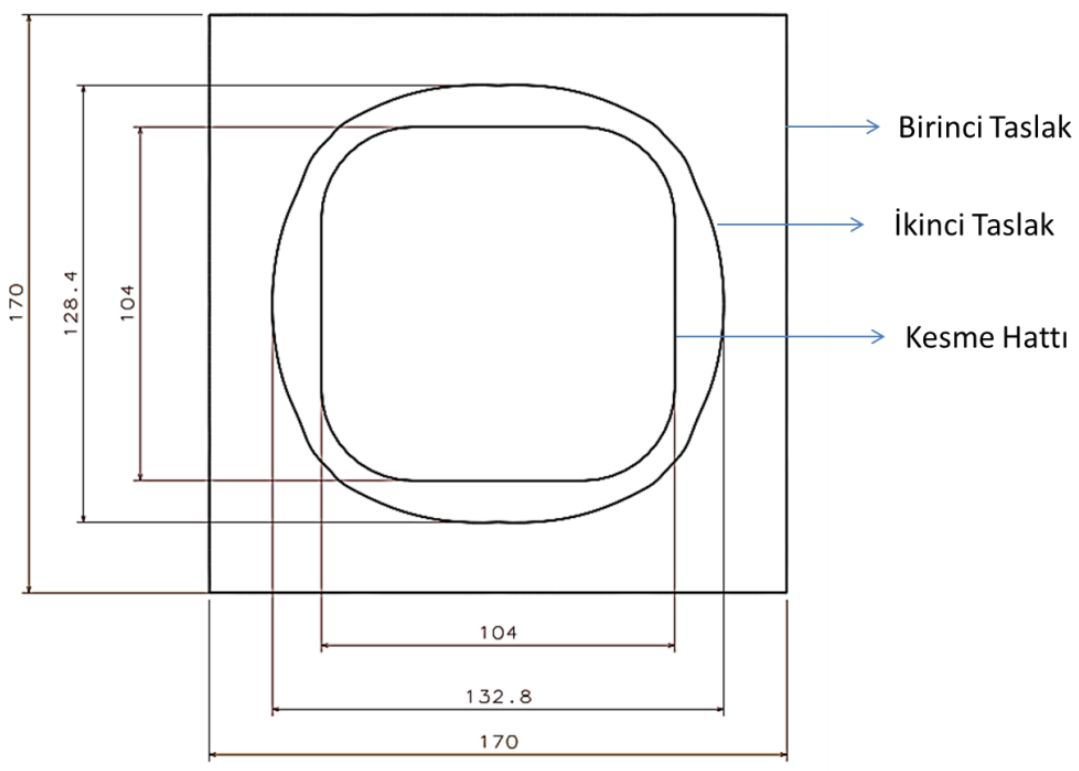

Şekil 7: Sac açınım boyutlarının karşılaştırılması

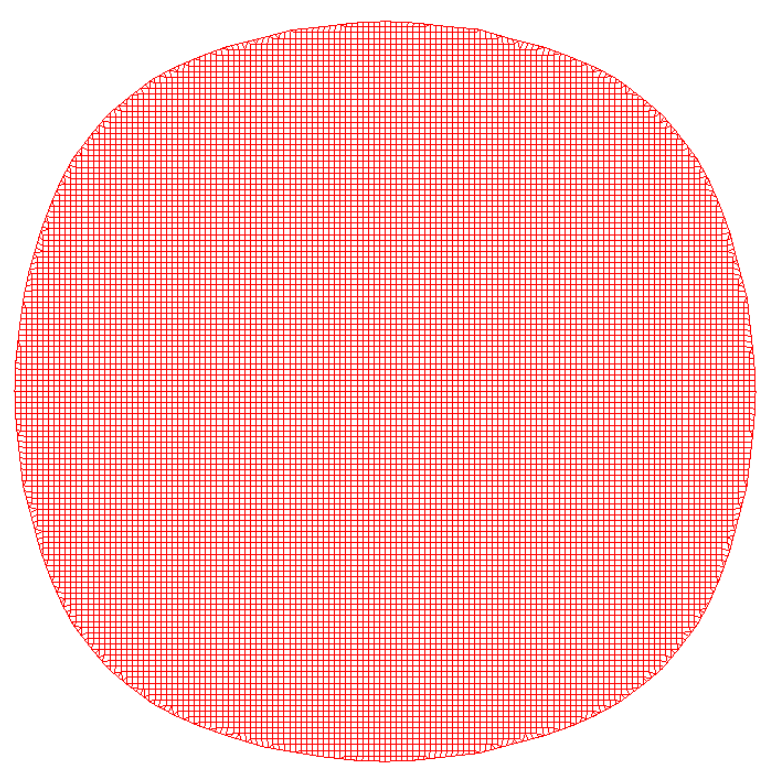

Şekil 8: Yeni sac açınımına ait ă̆ yapısı 


\section{SONUÇLAR VE TARTIŞMA (RESULTS AND DISCUSSIONS)}

Çalışmanın bu bölümünde her iki açınım geometrisi için gerçekleştirilen sonlu elemanlar analizi sonuçlarına yer verilmiştir. İlk olarak proseslere ait şekillendirme sınır diyagramları (FLD: Forming Limit Diagram) karşılaştırılmıştır. Karşılaştırma sonuçları Şekil 9'da gösterilmiştir. Sonuçlardan da görüldüğü üzere çekme miktarları aynı olmasına rağmen birinci sac açınımı sonucunda yırtılma olmamakla birlikte yırtılma riski olan bölgeler bulunmaktadır. Çalışma kapsamında geliştirilen yeni sac açınım geometrisi sonuçlarında ise ürün geometrisinin tamamı güvenli bölgededir. Bu durumun nedeni ilk sac açınımının flanş bölgelerinin daha geniş olmasından dolayı pot çemberi kuvveti altında gerdirme durumunun oluşmasıdır. İlk açınım ikinci açınıma göre daha yüksek gerdirme altında şekillendirilmektedir. Yeni sac açınımında ise flanş bölgeleri azaltıldığından gerdirme etkisi de azaltılmış ve parça geometrisi daha güvenli olarak şekillendirilmiştir. Benzer şekilde parçalardaki incelme sonuçları da incelendiğinde sac malzemede meydana gelen incelme oranının yeni sac açınımında daha düşük olduğu görülmektedir (Şekil 10). Bu durumun nedeni de yukarıda anlatılan gerdirme etkisidir. Sonuç olarak yeni sac açınımı ile aynı proses şartlarında ilk açınıma göre daha emniyetli ürünler elde edilmiştir. Böylelikle malzemedeki fire miktarının azaltılmasının yanı sıra şekillendirilebilirlik açısından daha güvenli ürünlerin de elde edildiği tespit edilmiştir.
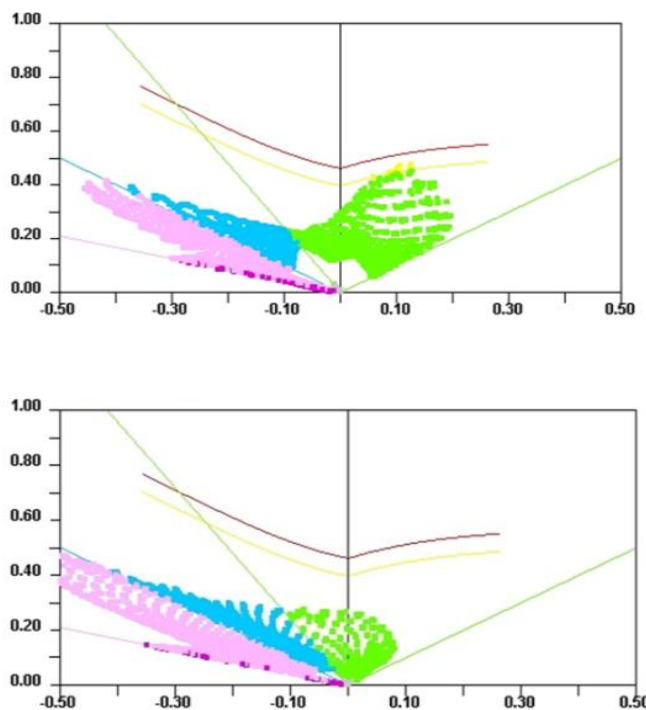

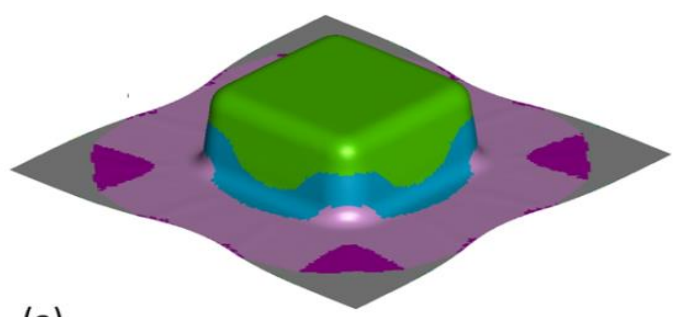

(a)

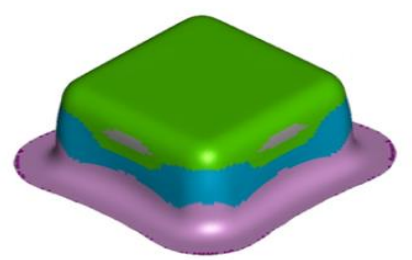

(b)

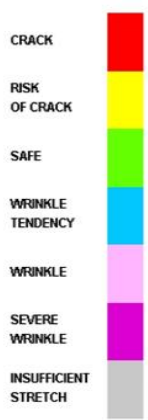

Şekil 9: (a) İlk açınım (b) Yeni açınım kullanılarak elde edilen FLD diyagramları 


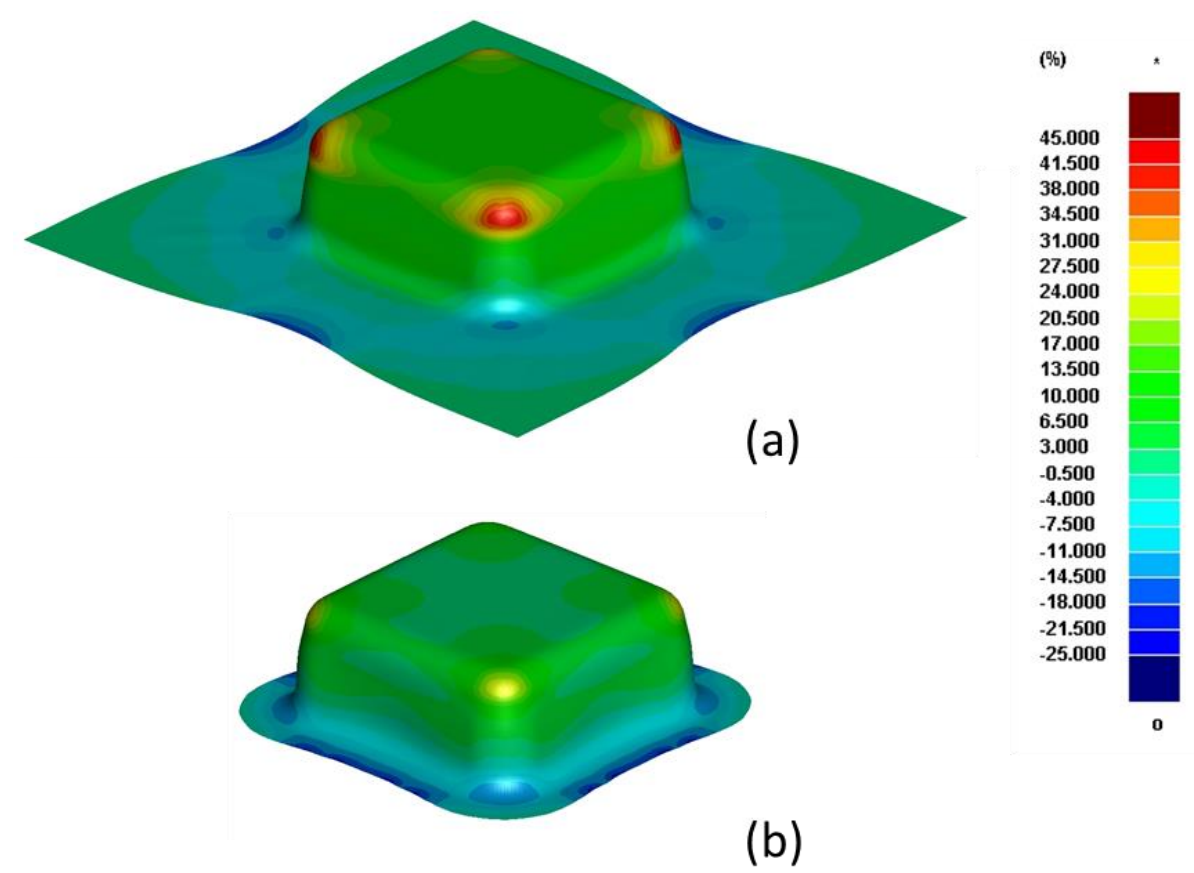

Şekil 9: (a) İlk açınım (b) Yeni açınım kullanılarak elde edilen \% incelme dağılımları

\section{DEĞERLENDİRME (CONCLUSION)}

Çalışmada kare çekme prosesi için çekme derinliği ve ürün geometrisini dikkate alan bir sac açınım geliştirme prosesi sunulmuştur. Malzeme olarak $1 \mathrm{~mm}$ kalınlığına sahip alüminyum 5754 alaşımı kullanılmıştır. İlk olarak kare çekmenin ilk açınımı olan 170x170 mm boyutlarında kare açınım kullanılmış ve bu açınımla sonlu elemanlar analizleri gerçekleştirilerek şekillendirilebilirlik ve \% incelme açısından ürün özellikleri incelenmiştir. Şekillendirilebilirlik açısından yırtılma oluşmasa da yırtılma riski bölgesinde olduğu görülmüş ve kalıbın omuz bölgelerinde yaklaşık $\% 45$ oranında incelme tespit edilmiştir. Sonrasında yeni bir sac açınımı hesaplanmış ve bu açınımla simülasyonlar gerçekleştirilmiştir. Sonuçlar incelendiğinde şekillendirilebilirlik özelliklerinde oldukça yüksek seviyelerde bir iyileşme elde edilmiş olup omuz bölgelerindeki incelme yaklaşık \%20 seviyelerine indirilmiştir. Yeni açınımla proses hataları açısından çok daha güvenli bir ürün elde edilmiştir. Bu durum, yeni açınımda flanş bölgelerinin kısaltılması ile pot çemberinin oluşturduğu germe etkisinin azaltılması sonucunda oluşmuştur.

Parça emniyeti dışında yeni sac açınımının malzeme fire miktarını azaltması hedeflenmiştir. Bu amaçla her iki sac boyutları endüstride kullanılan ortalama açınım boyutu olan 1600 x $1900 \mathrm{~mm}$ ölçülerindeki bir levha üzerinde gösterilmiştir (Şekil 10). Bu levhadan birinci açınımdan 90 adet ikinci açınımdan ise 143 adet ürün elde edildiği tespit edilmiştir. Bu durum maliyet açısından incelendiğinde yeni sac açınımının maliyet kazancının oldukça yüksek olduğu görülmektedir. Bu amaçla yakıt tankı gibi bir derin çekme işlemi ile ürün elde eden bir firma bu proses ile günde 100 adet parça ürettiği kabul edilirse 1 senede 36.500 adet ürün elde etmiş olmaktadır. 5754 alaşımının kilogram fiyatı ortalama 14,5 TL'dir [16]. Birinci açınım için 1600x1900x1 mm ölçülerindeki plakadan yaklaşık 405 adet, ikinci açınım kullanıldığında ise yaklaşık 255 adet gerekmektedir. Bu durumda çalışmada sunulan yaklaşımla hesaplanan sac açınımı sonrasında senede 150 adet plaka karı öngörülmektedir. Maliyet hesabı yapıldığında 1 plakanın ağırlığ1 $8,2 \mathrm{~kg}$ olduğundan 150 plaka $1230 \mathrm{~kg}$ olmaktadır. Bu durumda yeni açınımın kullanılması ile senede $1230 \mathrm{~kg}$ x 14,5 TL = 17.835 TL kar elde edilmektedir. Bunun yanı sıra yeni açınımın çevre uzunluğu ilk açınımın çevre uzunluğundan daha kısa olduğundan örneğin açınımlar lazer ile kesildiği düşünülürse üretim maliyetinde de bir azalma gerçekleşecektir. Sonuç olarak sac metal şekillendirme proseslerinde proses tasarımında sac açınımının optimize edilmesinin önemi açıkça görülmektedir. İlgili hesaplamalar bilgisayar destekli mühendislik araçları ile gerçekleştirildiğinde gerek zamandan gerekse de maliyetten elde edilecek karlılık miktarı daha da yüksek olmaktadır. 


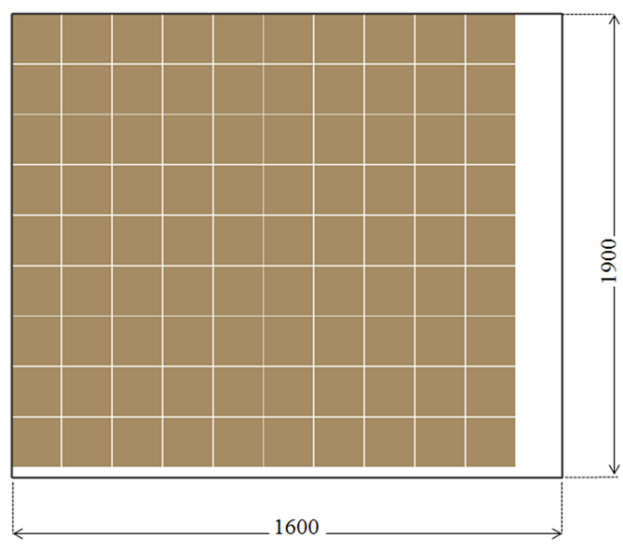

a)

90 Adet

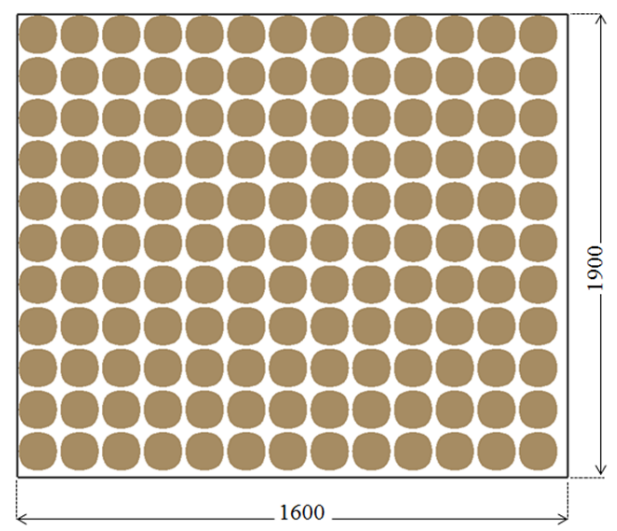

b)

143 Adet

Şekil 10: 1900x1600 mm ebatlarındaki levhadan elde edilebilecek sac açınımı miktarları a) Ilk Açınım b) Yeni Açınım

\section{KAYNAKLAR (REFERENCES)}

[1] D. Jiadong, M. Huajie, A blank optimization design method for three-roll cross rolling of complexgroove and small-hole ring. International Journal of Mechanical Sciences, 93 (2015) 218-228.

[2] A. Fazli, B. Arezoo, A comparison of numerical iteration based algorithms in blank optimization. Finite Elements in Analysis and Design, 50 (2012) 207-216.

[3] F. H. Yeh, M. T. Wu, C. L. Li, Accurate optimization of blank design in stretch flange based on a forward-inverse prediction scheme. International Journal of Machine Tools and Manufacture, 47: 12 (2007) 1854-1863.

[4] H. Naceur, Y. Q. Guo, J. L. Batoz, Blank optimization in sheet metal forming using an evolutionary algorithm. Journal of Materials Processing Technology, 151: 1 (2004) 183-191.

[5] M. Azaouzi, S. Belouettar, G. Rauchs, A numerical method for the optimal blank shape design. Materials \& Design, 32: 2 (2011) 756-765.

[6] R. De-Carvalho, S. Silva, R. A. F. Valente, A. Andrade-Campos, Blank optimization in a stamping process-Influence of the geometry definition. Finite Elements in Analysis and Design, 61 (2012) 75-84.

[7] M. C. Oliveira, R. Padmanabhan, A. J. Baptista, J. L. Alves, L. F. Menezes, Sensitivity study on some parameters in blank design. Materials \& Design, 30: 4 (2009) 1223-1230.

[8] R. Padmanabhan, M. C. Oliveira, A. J. Baptista, J. L. Alves, L. F. Menezes, Numerical study on the influence of initial anisotropy on optimal blank shape. Finite Elements in Analysis and Design, 45: 2 (2009) 71-80.

[9] R. Padmanabhan, M. C. Oliveira, A. J. Baptista, J. L. Alves, L. F. Menezes, Blank design for deep drawn parts using parametric NURBS surfaces. Journal of Materials Processing Technology, 209: 5 (2009) 2402-2411.

[10] M. H. Parsa, P. Pournia, Optimization of initial blank shape predicted based on inverse finite element method. Finite Elements in Analysis and Design, 43: 3 (2007) 218-233.

[11] M. Firat, Computer aided analysis and design of sheet metal forming processes: Part I - The finite element modeling concepts. Materials \& Design, 28 (2007) 1298-1303. 
[12] M. Turkoz, M. Dilmec, H. S. Halkaci, Investigation on Earing Behavior of AA 2024-T4 and AA 5754-O Aluminum Alloys. Advanced Materials Research, 264 (2011) 12-17.

[13] Aluminium Automotive Manual, European Aluminium Association, Ch. 5, (2011) 15.

[14] R. Hill, A theory of the yielding and plastic flow of anisotropic metals. Proc. Roy. Soc. London, (1948) 281-297.

[15] Ls-Dyna Theoretical Manual, Livermore Software Technology Corporation, 1998.

[16] İnternet, https://www.metalreyonu.com/urun/aluminyum-levha-1-mm-, Erişim tarihi: 17.05.2017. 